\title{
INVESTIGATION OF SINKHOLE AREAS BY THE USE OF ELECTRICAL RESISTIVITY TOMOGRAPHY: THE CASE OF PEDINI IN IOANNINA, GREECE
}

\author{
Fikos I. ${ }^{1}$, Vargemezis G. ${ }^{1}$, Kapeti F. ${ }^{1}$, Avramidou E. ${ }^{1}$ and Stylianou T. ${ }^{1}$ \\ ${ }^{1}$ Aristotle University of Thessaloniki, School of Geology, 54124, Thessaloniki, Greece, \\ ifikos@geo.auth.gr,varge@geo.auth.gr
}

\begin{abstract}
The Electrical Resistivity Tomography (ERT) method was used in order to study the karstic system in Pedini area (close to the city of Ioannina, West Greece) that is related with sinkholes whereby the drainage of the surficial water was possible.

The last five years floods are causing major problems in the area, since, the urbanization of the basin, in which the construction of a large highway is included, along with the increase of rainfalls produced a huge amount of water which the sinkhole was not able to drain any more.

The geophysical survey showed that the depth of the sinkholes is about 30 meters, proving their limited capacity to drain the basin to the desired level. At the same time, a fractured zone of high porosity has been revealed in the vicinity of the sinkholes.This zone can be used as to increase the capability of the sinkholes to drain the flood water. Keywords: ERT, infiltration, porosity, limestone.
\end{abstract}

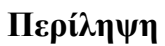

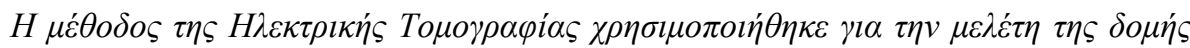

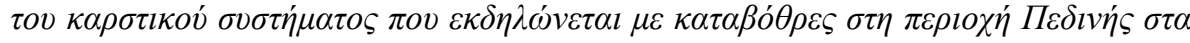

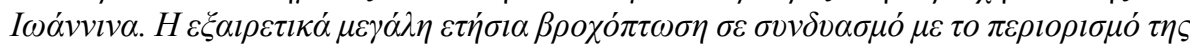

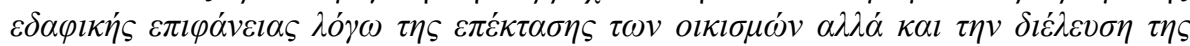

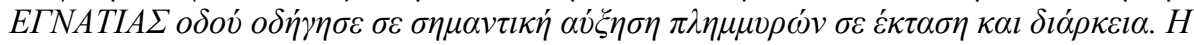

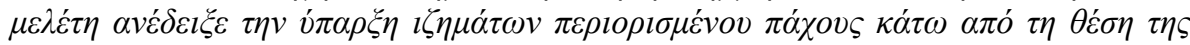

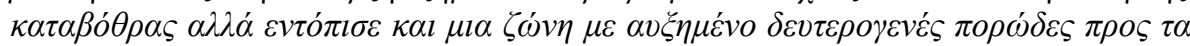

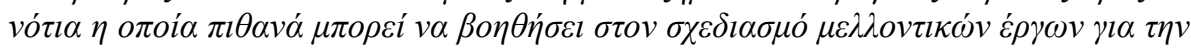

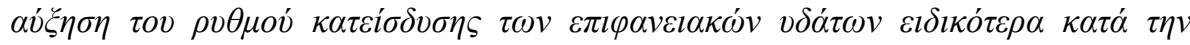

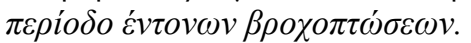

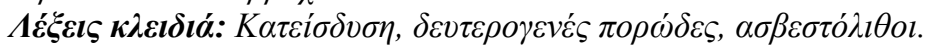

\section{Introduction}

The investigation of sinkholes has always been a very challenging problem for geophysics and the selection of the proper geophysical tool is not always straightforward. Schoor (2002) used resistivity tomography in order to detect mature sinkholes in Pretoria, South Africa. Bullock and Dillman (2003) applied GPR while Dobecki and Upchurch (2006) used also GPR in combination with ERT and P-wave refraction for small scale sinkholes in Florida. In common approach sinkholes and cavities near the surface are treated as potentially hazardous geological formations and the main target of any investigation is to identify them in order to avoid using the area in case of a future 
collapse. However, sinkholes in many occasions have significant hydrogeological role in the water equilibrium of small sized basins with limited surface outlet.

Based on statistics over the last decades the area of Ioannina has one of the highest precipitation rate of Greece every year, with an average of 124 days of rain per year and average annual precipitation of $1082 \mathrm{~mm}$ (http://www.currentresults.com/Weather/Greece/average-yearly-precipitation.php). The morphology of the broader area of Ioannina forms a basin, known as basin of Pamvotis, that doesn't have any significant physical surface outlet to any of the five large rivers surrounding this closed basin. The outflow of the huge amount of precipitation runoff is carried through the Lapsista's ditch and is diverted to the river Kalamas while the remaining water infiltrates and ends up to one of the numerous karst aquifers formed in the widely spread limestone rocks of the area. However, there are cases where small subbasins with no surface outlet, discharge only through sinkholes and in these areas floods can occur in cases of continuous rainfalls.

In the recent years the floods have increased in number, extend and duration due to the urbanization of large areas in the suburbs of the city of Ioannina, the completion of the Egnatia motorway crossing the area and also because of the lack of proper maintenance works in the most important and well known sinkholes that discharge these areas.

The subbasin of Pedini village has suffered greatly the last five years of floods that occupied large areas for periods that exceeded even three months duration and cause important financial and social problems to the houses, farmers, small businesses and large poultry farms that are hosted there. In an initiative undertaken by the local authorities and land owners in the area of Pedini, an ambitious attempt to study the sinkholes that exist in the basin started, in order to propose and build the necessary infrastructure so as to maximize the hydraulic load they discharge. As part of the necessary studies, the area in the vicinity of the Pedini sinkhole was investigated with the Electrical Resistivity Tomography method (ERT).

\section{Geology and Geomorphology}

The mountainous morphology forms a large basin called Ioannina, which is located in the central part of the Prefecture of Epirus hosting the city of Ioannina and the Pamvotis Lake. It has a size of approximately $425 \mathrm{Km}^{2}$. To the east, the watershed separates it from the Arachthos River. To the south, from the Loyros River, to the west from the Kalama River and finally to the north the watershed separates the basin from Voidomatis River and Zagoritiko River.The Ioannina Plateau is formed from carbonates aged from Jurassic to Cretaceous and Eocene (Marnelis, 2007). In particular, the Ioannina basin was formed by tectonic movements that led to the development of synclines and anticlines of the Ionian Zone, with subsequent faulting and sedimentation at the end of the Pliocene and during the Quaternary. Karst solution of the limestone basement led to the development of a closed depression or polje. The basin is formed on a syncline and is bordered by $\mathrm{N}-\mathrm{S}$ and $\mathrm{E}-\mathrm{W}$ trending faults (IGRS-IFP, 1966), suggesting that a Late Pliocene to Early Pleistocene phase of fluvial deposition occurred which sealed the basin floor and the onset of continuous sedimentation. The main geological units observed in the Ioannina area are (Perrier et al., 1967; Brousoulis et al., 1999) (i) Pantokrator limestone, (ii) Posidonia Beds of siliceous clay and cherts and (iii) Vigla limestone (iv) Senonian limestone (v) Palaeogene limestone (vi) Flysch. Finally during the Quaternary sedimentation mudstones, sands and gravels covered the flysch or limestone bedrock in many parts of the area.

Ioannina basin can be divided into two smaller basins, the first, known as Pamvotis basin that occupies approximately $236 \mathrm{Km}^{2}$ of the eastern and western part of Ioannina basin and drains to the homonym lake. The second, called Lapsista Ditch basin that drains to the northwest through the homonym ditch to the Kalama River. Apart from these, there are a number of larger and smaller subbasins that are formed completely isolated from the rest of the Ioannina basin and discharge only through sinkholes. 
The drainage system of this karst landscape comprises of numerous different size streams that usually end up and disappear under scree and alluvial deposits.

Focusing to the area of Pedini, the geological map shown on figure 1 reveals that the broader area of the sinkhole is covered by extended alluvial deposits (al) with unknown thickness. To the east, there are deposits of siliceous clay and cherts originating from the Vigla limestone while deeper breccia limestone formations can be found. In the area of the sinkhole of Pedini these limestone appear on the surface as a result of some unknown geological and/or tectonic process. The precise location of the known sinkhole coincides with the surface boundary of the above mentioned limestone and the alluvial sediments. This boundary appears in the form of a very sharp change in the morphology of the area.

The sinkhole has rather small size at its present state with only 3 meters diameter but according to the local authorities from time to time smaller sinkholes appear and then disappear suggesting that the surrounding area can on occasions function as one large sinkhole.

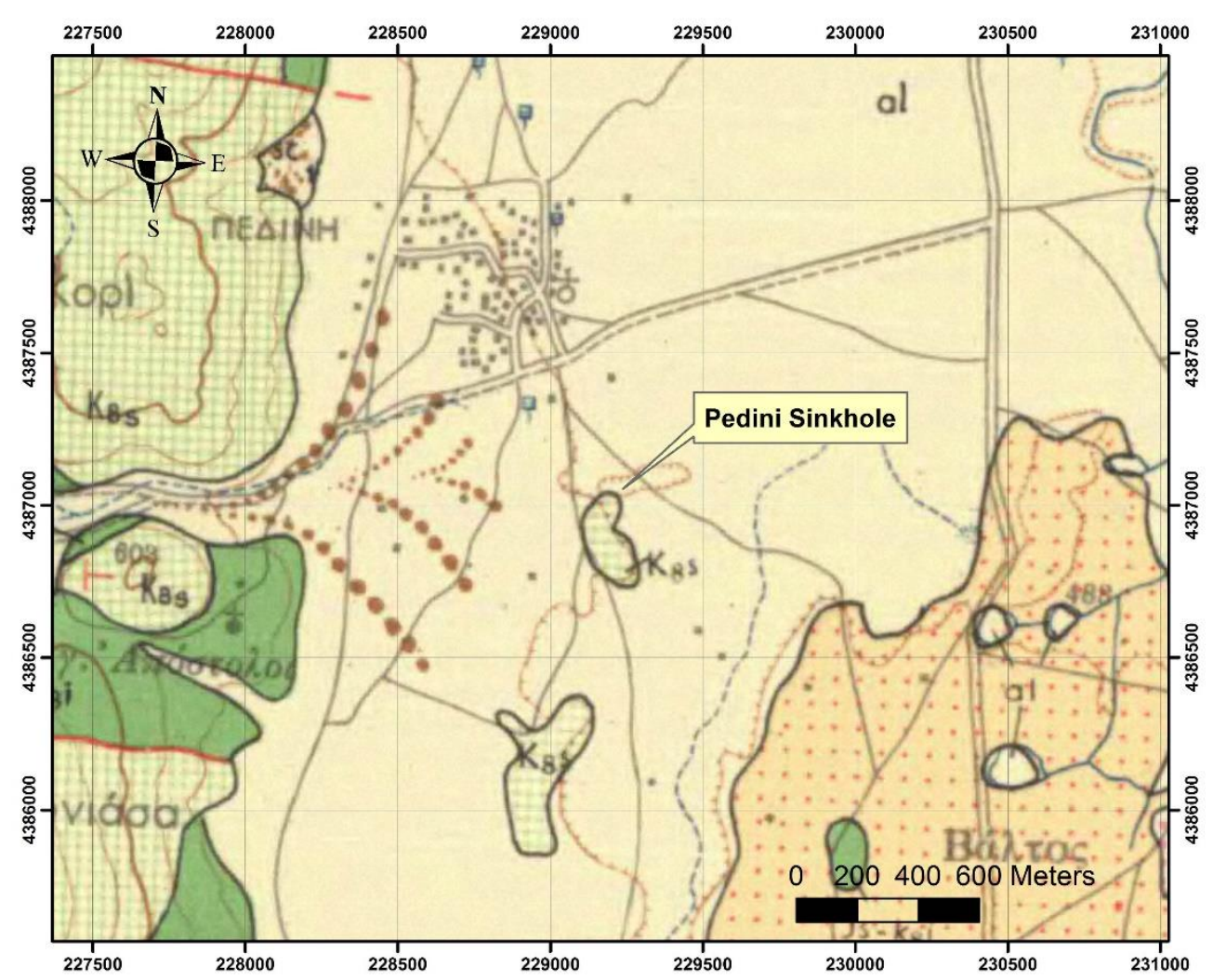

Figure 1 - Geological map of the area of interest (I.G.M.E. Ioannina 1:50000).

\section{Geophysical Investigation}

\subsection{Methodology}

The objective of this work was to provide, in very short time, valuable information for planning and designing the necessary infrastructure that could help reduce the flooding of the broader Pedini basin. The complex geological regime of the area in combination with lack of deep drilling data for the area near the sinkhole led to the choice of geophysical investigation of the subsurface near the sinkhole. 
The Electrical Resistivity Tomography method was chosen in order to study in detail the geological formations, the possible fractures and/or karst for the first tenths of meters underneath the sinkhole gathering. The same method was also used for providing information for the geology in a larger scale and to depths down to more than 200 meters.

In this respect we measured 4 ERT lines (ERT1, ERT2, ERT3 and ERT4) with 24 electrodes and electrode spacing ' $a$ ' equal to 10 meters, all located in very small distance from the sinkhole area as presented in figure 2 . This layout gave us a total length of approximately 230 metres and maximum depth of investigation close to 100 metres. We also measured 2 more ERT lines (ERT7 and ERT8) using 21 electrodes and electrode spacing 'a' equal to 50 meters resulting in a total length of 1000 meters and maximum depth of investigation greater than 200 meters for each ERT. The location of these lines can be seen in figure 2 .

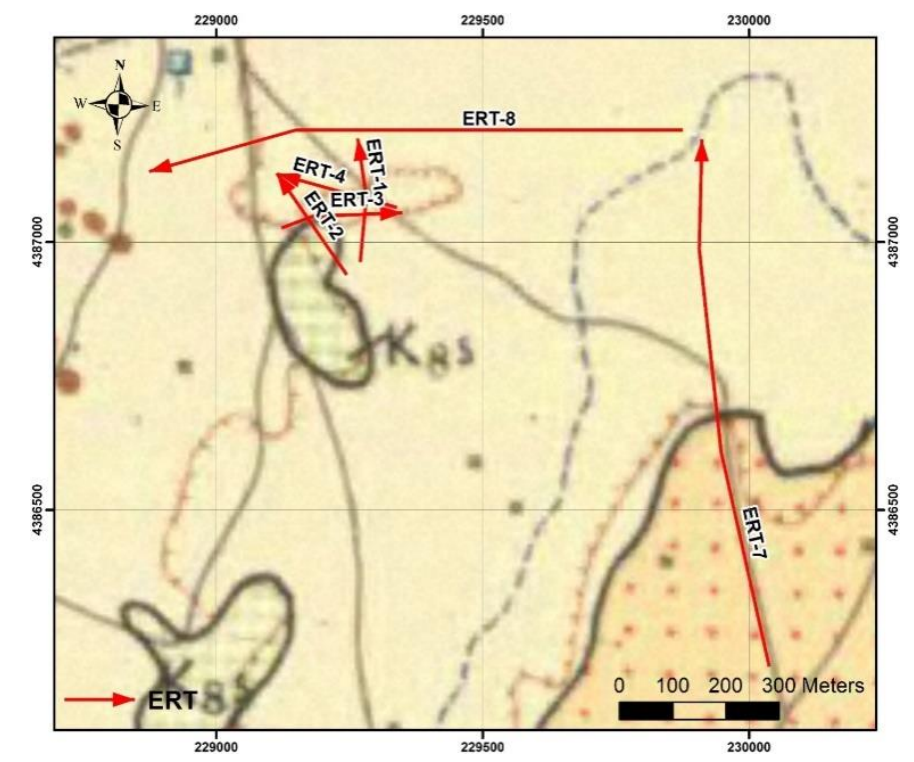

Figure 2 - Locations of the six ERT lines measured in Pedini sinkhole area.

\subsection{Measurements and results}

The measurements were collected using the Syscal Pro resistivity meter by IRIS INSTRUMENTS using an optimized array (Athanasiou et al., 2007) designed for taking advantage of the best measurements, in the sense of sensitivity, from more than one typical array (e.x. dipole - dipole). The measurements were inverted using the DC_2DPro inversion software (Kim, 2012) and the results are presented in figures $3-8$, showing the resistivity distribution of the subsurface. The location of all the electrodes was measured with the help of a differential GPS and the precise altitude was used in the inversion algorithm to take into account the topography variations and the RMS error calculated for each one varied between $7 \%$ and $11 \%$.

In the results, the vertical axis is showing the elevation in meters above sea level (a.s.l) while the horizontal axis is the distance along the ERT line following the direction of arrows shown in figure 2. The color scale used in all these figures is a rainbow color scale with the blue shades representing low resistivity values and red - purple representing high resistivity values. The black stars in the figure of ERT4 shows the exact location, in relation to the ERT line, of the 2 most important sinkholes currently visible on the surface.

The resistivity distribution calculated for all the ERT lines reveals a significant variation from very low values, on the order of few Ohm-m that are typical values for rich clay content sediments, up to hundreds or even thousands of Ohm-m that correspond to bulk rock. The images suggest a very 
complex geological structure that is in agreement with the geological regime of the broader area. Sudden lateral changes from high or very high values to low values (i.e. ERT2 or ERT7) can be interpreted as tectonic features that are expected in the broader area.

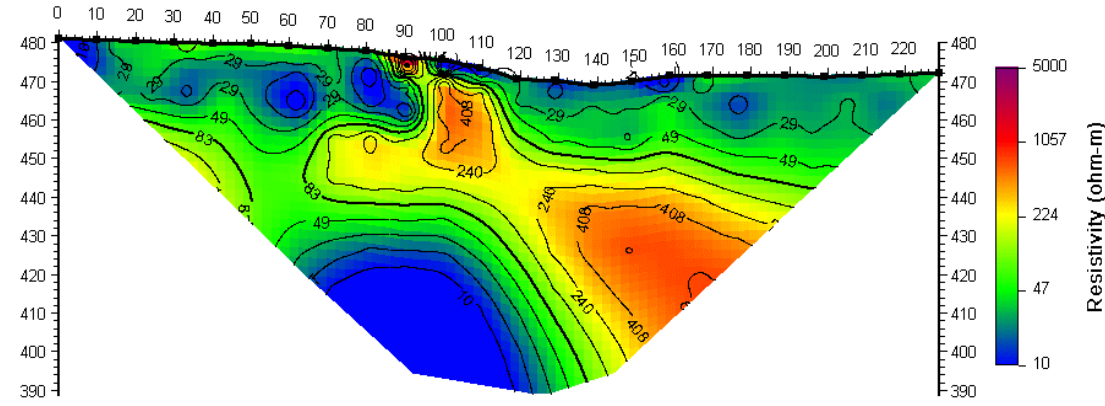

Figure 3 - ERT1 Calculated resistivity distribution.

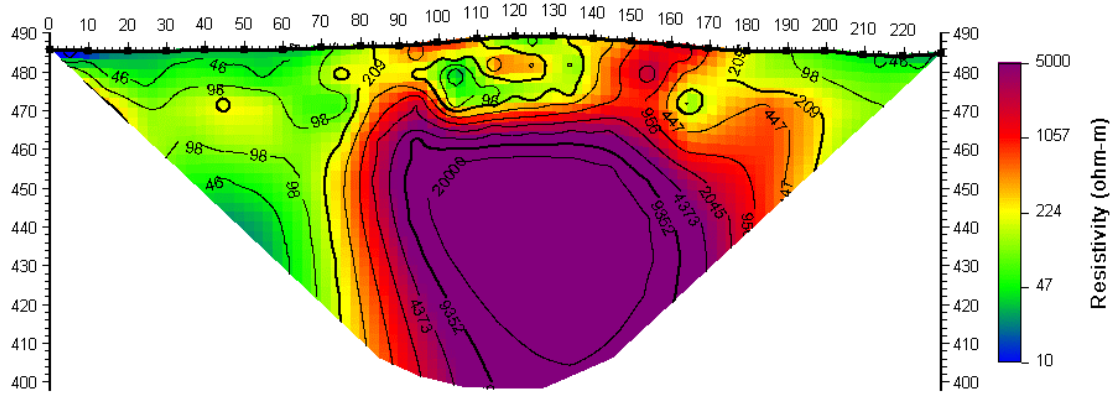

Figure 4 - ERT2 Calculated resistivity distribution.

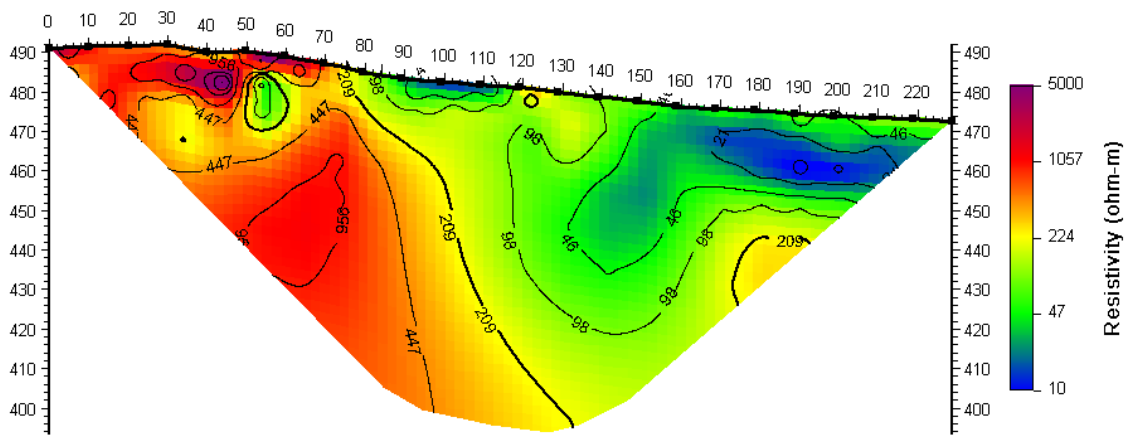

Figure 5 - ERT3 Calculated resistivity distribution. 


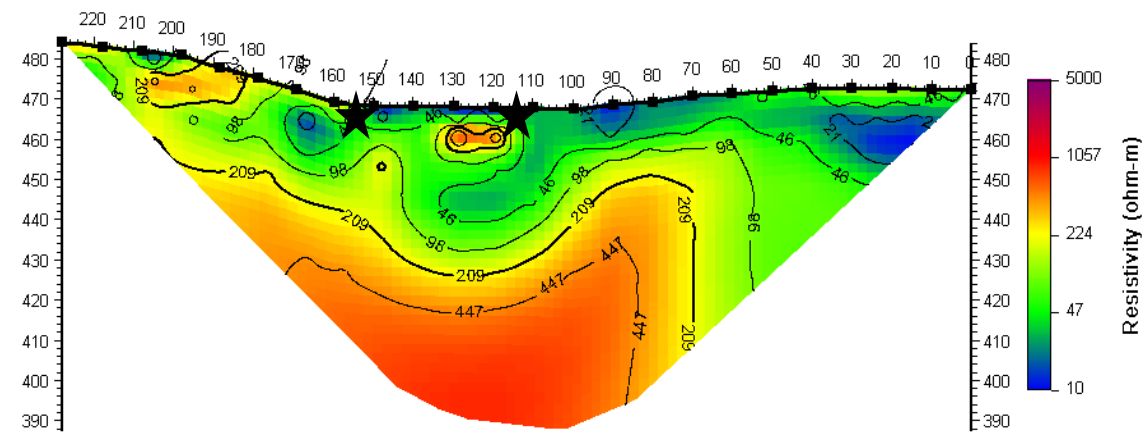

Figure 6 - ERT4 Calculated resistivity distribution.

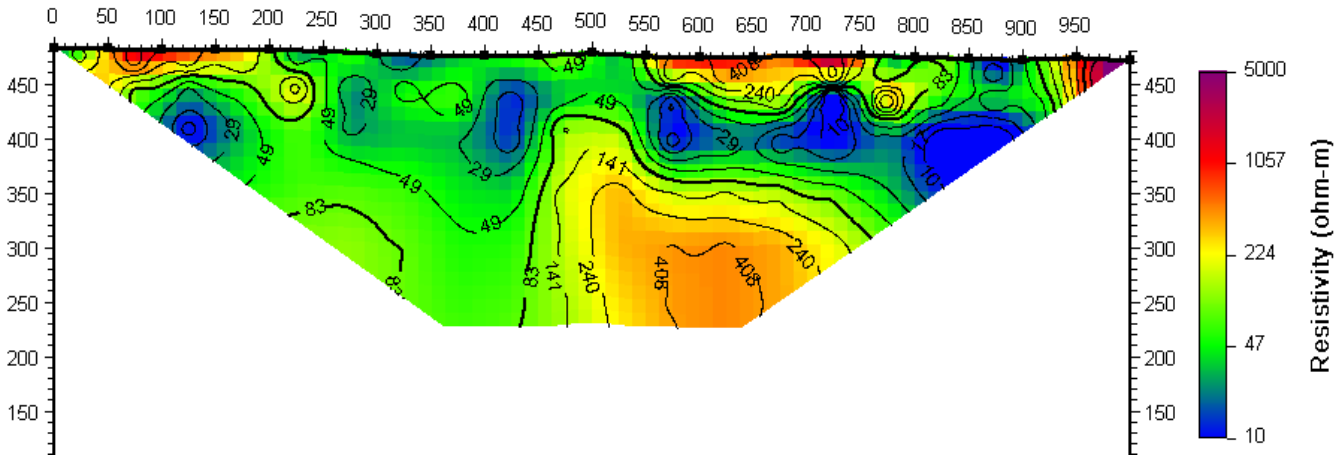

Figure 7 - ERT7 Calculated resistivity distribution.

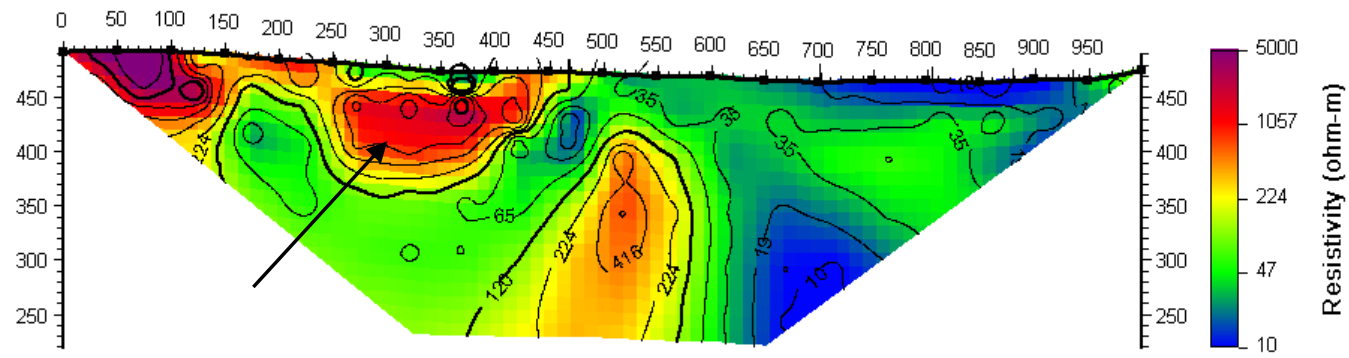

Figure 8 - ERT8 Calculated resistivity distribution.

If we group together ERT1 and ERT2 that have more or less south - north direction we can see that in both cases there is a rather conductive area (formation) towards the southern part of each ERT that switches to a very resistive formation as we move north. The boundary especially in ERT2 is very sharp and can possible be attributed to some tectonic discontinuity.

Similarly by grouping together ERT3 and ERT4 we observe that in both cases the western part of the lines is occupied by resistive formation which switches to a more conductive one towards east. The boundary of these different formations (resistive-conductive) is quite sharp thus suggesting a possible tectonic discontinuity again. In the case of ERT3 and ERT4 and, in different scale, also in ERT8 we observe that there is a rather extended and thick conductive layer with values that suggest the existence of clay to the east of Pedini sinkhole area explaining limited infiltration taking place in the broader area during the flooding. 
Especially for the case of ERT4 that crosses only few meters away from the sinkholes, it is shown that underneath this area the resistive body, attributed to limestone, forms a small basin, filled with sediments with an average resistivity of $40 \mathrm{Ohm}-\mathrm{m}$ and maximum thickness less than 50 meters.

In such complex geology the three dimensional representation of the resistivity distribution of the 6 ERT line measured proved critical in order to combine the different possible tectonic discontinuities revealed by the two dimensional resistivity distribution calculated for each ERT. A snap shot from southwest, presented in figure 9, suggests that there might be just one tectonic feature crossing ERT1, ERT2, ERT3, ERT4 and ERT8 with a general southwest - northeast trend (black thick line in figure 9).

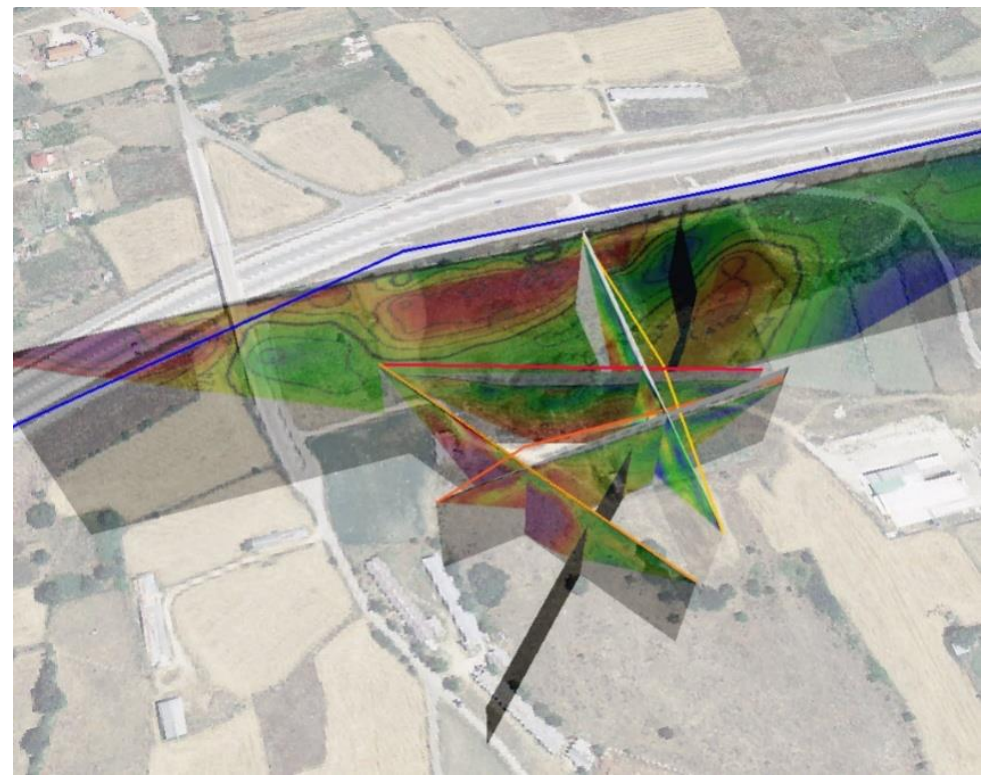

Figure 9 - three dimensional representation showing the five ERT lines in the vicinity of Pedini sinkhole. The black surface corresponds to a possible fault line assumed by these data.

\section{Conclusions and discussion}

The ability of ERT measurements to examine fast and accurately the geological structure in combination with the advantage of being able to focus in different depths in order to get a better understanding of the geological regime in different scales for the same region proved very useful for the study of Pedini sinkhole.

The ERT investigation managed to map the thickness of the top layer sediments that cover almost the entire broader area. The resistivity distribution suggests that there is a solid impermeable rock (limestone), in small depth underneath the location of the sinkholes, forming a small basin there. This rock is interrupted to the east and south by a SW-NE fault crossing the area. The fractured zone is depicted with $30 \mathrm{Ohm}-\mathrm{m}$ to $50 \mathrm{Ohm}-\mathrm{m}$ suggesting increased porosity and presumably high to very high values of hydraulic permeability.

Another interesting feature is revealed by ERT8 where the large resistive body identified close to the surface and between 250 and 400 meters along the $\mathrm{x}$ axis of the tomography (black arrow in figure 8) coincides in location and size with the resistive body occupying the central and western part of ERT4 and ERT3 respectively. The depth of investigation in these two tomographies does not exceed 100 meters (or 400 meters a.s.1.) but in the case of ERT8 the investigation reaches greater depths, far below 400 meters a.s.l. and implies that the above mentioned resistive body disappears just below 370 - 360 meters altitude replaced by sediments with possible high water content. 
Further investigation with drilling and investigating the hydraulic characteristics of the identified permeable zone east of the location of the sinkhole combined with a more extensive geophysical investigation could strengthen the idea that this permeable zone could be exploited for infiltrating the surface water in the underground faster and therefore minimise the flooding.

\section{References}

Athanasiou, E., Tsourlos, P. and Vargemezis. G., 2007. Optimizing Electrical Resistivity Array Configurations for Hydrogeological Studies. In: Coastal Aquifers: Challenges and Solutions, Pulido Bosch, A., Lopez- Geta, J.A. and Ramos Gonzalez, G., eds., Hidrogeologia y agues subterraneas, Instituto Geologico y Minero de Espana, Madrid. 23, 243-252.

Brousoulis, J., Ioakim, C., Kolovos, G. and Papanikos, D., 1999. The Ioannina basin: geological and palaeoenvironmental evolution in Quaternary and historical times, British School at Athens Studies, 3, 87-96. Retrieved from http://www.jstor.org/stable/40960216.

Bullock, P.J. and Dillman, A., 2003. Sinkhole Detection in Florida Using GPR and CPT. Presented at the $3^{\text {rd }}$ International Conference on Applied Geophysics, Hotel Royal Plaza Orlando, Fla., Dec. 8-12, 2003.

Dobecki, T.L. and Upchurch, S.B., 2006. Geophysical applications to detect sinkholes and ground subsidence: The Leading Edge, 25, 336-341, doi:10.1190/1.2184102.

IGRS-IFP, 1966. Etude Geologique de L'Epire (Grece Nord-Occidentale), Paris, Technip Editions, $306 \mathrm{pp}$.

Kim, J.H., 2012. DC 2DPro v. 0.99. User's Guide. http://kigam.en.ecplaza.net/.

Marnelis, F., Roussos, N., Rigakis, N. and Karakitsios, V., 2007. Structural geology of the western Greece fold and thrust belt. - AAPG, 14-17 Nov. 2007, Guide to Fieldtrip No.1, 47 pp.

Perrier, R., Potier, L., Sayoyat, E., Koukouzas, K. and Monopolis, D., 1967. Geological map of Greece: Ioannina map sheet, scale 1:50,000, Institute of Geology and Subsurface Research, Athens, Hellas.

Van Schoor, M., 2002. Detection of sinkholes using 2D electrical resistivity imaging, Journal of Applied Geophysics, 50, 393-399. 